European Management Journal, 20(6), p.671-679

Congruent, Divergent and Incoherent Corporate Level Strategies

Cliff Bowman, Keith Ward and Andrew Kakabadse

Cranfield School of Management

Cranfield, Beds

MK43 OAL UK

Tel: +44 (0) 1234751122

Fax: (0) 1234750070

Email: c.bowman@ cranfield.ac.uk 


\begin{abstract}
This paper draws together four related strands of theory to address the processes of corporate value creation. Specifically, contributions from resource-based theory, dynamic capabilities, corporate strategy and Mintzberg's structure theory have been combined to derive four congruent resource-creating strategies: financial control, scale, leverage, and creativity. Mintzberg's configurations approach is used to explore the organisational structures and processes associated with each strategy. It argues that choices with respect to corporate resource creation must be made as these four strategies require distinct, congruent organisational arrangements. When congruent strategies deliver diminishing returns, divergent strategies may be pursued. However, there is a risk of incoherence where a divergent strategy is poorly implemented.
\end{abstract}




\section{Congruent, Divergent and Incoherent Corporate Level Strategies}

The resource-based view ${ }^{1}$ provides insight into the stock of value creating resources inside the firm. More recently, this literature has been augmented by contributions which focus on the processes of resource creation, termed dynamic capabilities ${ }^{2}$. Typically these arguments are addressing firm or strategic business unit level strategy, as the value of resources is discussed in terms of their contribution to the achievement of competitive advantage. But these theoretical developments offer us an opportunity to re-visit corporate level strategy. In what follows we draw on insights from the resource based view, dynamic capabilities, the corporate strategy literature ${ }^{3}$ and the notion of configurations to develop four coherent corporate resource creating strategies. They are coherent in two respects. First, the structures and processes associated with their implementation are internally supportive, and second corporate level and SBU level strategy are aligned.

We then argue that at some point in the development of the corporation a particular congruent configuration will exhaust its value creating potential. This leads us to speculate on the possibility of divergent strategies where there are fundamental differences of strategic orientation at corporate and SBU level. We then explore the implications for leadership if successful divergent strategies are to be implemented.

\section{Four Congruent Configurations}

Drawing on recent contributions to the resource based view, particularly the notion of dynamic capabilities we can suggest that there are four distinct modes of corporate value creation. Each of these modes exploits particular dynamic capabilities to create new corporate value creating resources, which may be located within the SBUs or they may be at the 
corporate centre. Three higher level capabilities identified by Teece et al, (reconfiguration, replication and learning) have informed an exploration of the organisational consequences of enacting these capabilities.

1) Financial Control: here the centre causes SBU resources to be developed through the setting and administering of tough financial controls. Appropriate capabilities include SBU acquisition and resource allocation routines, accompanied by a process of provoked learning within SBUs.

2) Scale: the centre delivers the resource by reconfiguring support activities and/or core processes to exploit economies of scale.

3) Leverage: the centre creates new SBU resources through replication, by codifying and transferring know-how that originates from the centre, or from SBUs.

4) Creativity: the centre encourages and facilitates learning that leads to product or process innovation. Here the centre is aiming to set up "webs of collaboration" across the corporation.

These can be viewed as alternative corporate strategies, and each one is likely to call for a particular combination of organisational structures and processes. Mintzberg's ${ }^{4}$ notion of configurations can help us draw out the organisational implications of theses differing corporate value creation strategies. Mintzberg argues that there are congruent combinations of structures, and processes that match particular sets of contingent conditions. Five of the 
six commonly occurring configurations he describes can be regarded as essentially firm-level phenomena (the entrepreneurial, machine, professional, missionary and adhocratic configurations). The multidivisional structure is his sixth configuration, which we are attempting to elaborate here by exploring the structural and process implications of these different corporate level strategies.

Drawing on the concept of configurations, we can identify the differing design parameters that are likely to be associated with each of these corporate strategies. The resulting alignment of strategic intent and organisational structures and processes we label a congruent corporate strategy.

The idea of congruent configurations can be traced back to the early empirical studies of organisations conducted by, for example Chandler, Burns \& Stalker and Lawrence \& Lorsch $^{5}$. Miles \& Snow ${ }^{6}$ and Mintzberg have developed the approach, and in the strategy field Porter $^{7}$ could also be seen to be pursuing a configurational argument.

The reason for adopting this approach here is rooted in a belief that strategy and structure should not be treated as separate phenomena. A strategy will have distinct and particular organisational requirements if it is to be realised. So realised strategies and structures are inextricably connected. Organisational structures and processes should be regarded as partial descriptions of realised strategy, or, to put it another way, intended strategy is enacted through extant structures and processes. Therefore, although intended strategies $^{8}$ can exist in an ideal form, realised strategies cannot. With intended strategies we can detect likely mismatches between strategy and structure, but with realised strategies structures and processes become part of the description of strategy. If we are able to establish feasible links 
between our four strategies and organisational structures and processes, this lends weight to the argument that the strategies are not merely ideal constructs.

\section{Insert Table 1 about here}

In Table 1 we have suggested that each strategy requires distinct combinations of design parameters. We have adapted Mintzberg's original set of parameters, and have focused on those most likely to vary by corporate strategy. These are:

- SBU strategy autonomy

- SBU performance measures

- Co-ordination across levels (between the centre and SBUs)

- Co-ordination across SBUs.

Table 1 also explains the role of the centre in each strategy, the location of "resources", and the requirement for SBU similarity if the strategy is going to add value. It also suggests which dynamic capabilities are likely to be in evidence. Moreover, there are some parallels between each strategy and Mintzberg's original work, because each strategy can be associated with a predominant co-ordination mechanism, and a predominant part of the organisation. Figure 1 depicts each strategy with adaptations of Mintzberg's original 'logo'. We can now explore the required configurations for each resource creating strategy in more depth, starting with the financial control strategy.

Insert Figure 1 about here 


\section{Financial Control}

A familiar strategy adopted by diversified conglomerates, the financial control strategy creates SBU resources through a tough governance regime. The setting of stretching targets provokes learning in the SBUs, which have autonomy over means, or strategy, but not ends. Co-ordination between the centre and the SBUs is minimal, as is co-ordination across the disparate collection of SBUs in the portfolio. The prime co-ordination process is the standardisation of financial outputs. The key part of the organisation is the strategic apex that sets the targets, and changes the mix of SBUs. Critical is the application of managerial skills, which are transactionally focused on detail and require disciplined application from both Centre and SBU managers. The relentless nature of continuous attention to the numbers requires an uncompromising sense of diligence.

Hence classic examples of financial control groups were diversified conglomerates such as Hanson, Tomkins, and the old forms of BAT Industries and GEC (now renamed Marconi). Less diverse groups such as Saatchi \& Saatchi and WPP have applied the rules of this configuration in their initial rapid growth strategies.

\section{Scale}

Here reconfiguration of core or support activity results in resource creation at the centre. If support functions are consolidated to achieve cost reductions there is no strong requirement for SBU strategies to be strongly co-ordinated. However, where SBU activities are closely coupled to centralised core processes then strong co-ordination is required between the centralised activities and the remaining sub-set of activities that are conducted in SBUs. For example, the SBUs may be restricted to geographically distributed sales and service activity, having to rely on centralised manufacturing processes. At the centre, co-ordination is effected 
through direct supervision of support and/or core activities to ensure the achievement of scale advantages. The centralised operating core and the line management who control it are the key parts of the structure. The style of management adopted is hierarchical (top down) and at times, blatantly so, in order to highlight the philosophy of centralisation. In circumstances of resistance confrontational rather than co-operative approaches to conflict resolution are likely to be more effective.

This configuration is utilised by several industries which have undergone, or are still in the process of, major consolidations in order to reduce costs or gain critical mass for key business processes (e.g. automotive manufacturing, pharmaceuticals and financial services).

\section{Leverage}

In the leverage strategy the centre's role is to replicate knowledge-based resources across the mix of SBUs. Thus the centre is required to identify, codify and transfer know-how. SBUs have some strategy autonomy, but they would be required to adopt standardised systems, and to co-operate with other SBUs in the replication process. Thus Mintzberg's technostructure, those staff at the centre engaging in the replication processes, are the key part of the organisation. Leadership rather than good management is required, as promoting knowledge replication will involve attention to contextual factors. Although the centre challenging the 'moves' of each SBU in the organisation would be received as unwelcome, the unique nature of each unit is likely to make the pursuit of managerial templates unlikely.

Businesses which are trying to replicate specific skills from one area or SBU are utilising the leverage configuration. Several fast moving consumer goods groups (such as Unilever, Procter and Gamble, Nestle and Philip Morris) and the Disney group have sought to leverage 
their brand management and customer service expertise across a wider range of products and sectors. For instance, Nestlé's acquisition of Rowntrees has led to a dramatic development and extension of core confectionery brands like Kit Kat and Polo.

\section{Creativity}

Here learning within SBUs is encouraged and supported by the centre, but in addition the centre engenders cross-SBU dialogue. The key part of the organisation is the culture, or ideology. Values of collaboration, and sharing information and ideas in the corporate interest are critical. SBUs should have complementary knowledge and experience sets that can spark off each other to create new ideas. These may be profitably developed within existing SBUs, or indeed new SBUs may need to be established to exploit the new resource. Similar to the leverage strategy, new and further learning is likely to be achieved through leadership by example, thus promoting a climate of open dialogue and challenge. Senior management need to live the corporate philosophy of creativity and dynamism by making themselves available for feedback and exhibiting a robustness for the 'cut and thrust' of ideas exchange.

Creative configuration groups include 3M, Canon and Cisco where maintaining the culture of the organisation is seen as the critical role of the centre. Interestingly, but not surprisingly, this configuration becomes even more challenging as the business succeeds and grows. This is particularly true where this success is based on a single product range (e.g. Microsoft and Intel), and the business may, by default, migrate to the leverage configuration with a greater degree of direct intervention from the centre. The company may need a significant restructuring if it desires to move back to its original creative configuration, so as to maintain its original winning culture and value system. 


\section{Incoherent Strategies}

As is clear if one reads across the rows of Table 1, each strategy is distinct in the organisational structures and systems it requires. This may suggest that where there is clarity concerning the corporate value adding strategy, the corresponding congruence of the design parameters may be associated with good performance. Conversely mismatches between the espoused corporate strategy and the design parameters may lead to poor results. Moreover, where corporate management strive to achieve the benefits of more than one value adding strategy the relevant design parameters may be compromised, resulting in an incoherent strategy. Thus one key conclusion from this configuration argument would be that corporate executives need to be very clear on the predominant resource creation strategy they are pursuing. This is because the realisation of the selected strategy requires a particular set of organisational arrangements, and failure to align corporate processes according to the demands of each strategy is likely to be sub-optimal. Similarly, attempts to pursue two resource-creation strategies simultaneously may well result in disappointment, as in the absence of appropriate structures and processes, further resource development is likely to be constrained.

However, scrutiny of the table suggests that some strategies may co-exist without too much conflict between the required design parameters. For example, one might envisage a corporation pursuing leverage and creative strategies simultaneously without undue conflict between the parameters: both require the centre to establish a culture of co-operation across levels and between SBUs, where SBU goals would reflect both financial and non-financial performance, and both require some complementarity across the mix of SBUs. 
We might envisage conflicts where the espoused strategy is creativity, but the pressures experienced by SBU management may well be those associated with a financial control strategy. Similarly, where SBU autonomy is severely constrained by the requirement to use corporate resources, as in the extreme scale style of configuration where core processes have been centralised, setting tough bottom line targets to SBU management which are more suited to the financial control style may be extremely de-motivating. In Figure 2 we have positioned the four strategies according to the extent of SBU strategy autonomy they permit, required SBU similarity, and the co-ordination requirements. We have located two versions of the scale strategy: Scale 1 refers to the consolidation of support functions, and Scale 2 refers to the achievement of scale economies in core processes.

This mapping of the strategies on these dimensions suggests where the tensions between strategies might primarily stem from. Where strategies are adjacent in Figure 2, we could conclude that they might be pursued concurrently without exerting undue tensions and conflicting demands on the organisation's structures and processes. The corporate executives could therefore direct attention to minimising the effects of these design parameter compromises.

\section{Insert Figure 2 about here}

\section{Sustainability of Corporate Strategies}

Adopting an RBV, and specifically a dynamic capabilities approach to corporate strategy enables us to explore the nature and durability of some sources of corporate advantage. We might suppose that these sources of advantage would vary in the extent to which they can be replicated. It would seem that certain corporate capabilities are more susceptible to imitation than others. For instance, we might expect that the consolidation of generic activities to 
reduce certain overhead costs (as in the Scale 1 strategy), might be readily replicable by rival corporations. But when we consider the leverage strategy, the capability to identify a knowledge resource, to codify it, to identify where else it may give advantage, and to create the climate that facilitates the embedding of this know-how in other SBUs, we might conclude that this capability may be very difficult to replicate.

Similarly, the ability to foster the climate of trust, required in the creative configuration, one where staff from different SBUs would feel free to collaborate, and where the pervading culture supports innovation and countenances "failure" may be corporate advantages that are very difficult to copy.

The sustainability of corporate advantage is likely to depend on both the quality of strategy execution, and the ease with which the strategy can be imitated. As argued earlier one critical dimension of execution is the alignment or congruence of the design parameters set out in Table 1, with the espoused strategy. The key parameters as set out in Figure 2 are likely to be SBU autonomy, performance measures, and co-ordination across levels, and across SBUs. A lack of coherence is likely to lead to a reduction in the effective delivery of the espoused strategy.

The ease with which the strategy can be imitated will be determined by the same variables that prevent resources from being imitated e.g. social complexity, embeddedness, codifiability, path dependency etc. We might expect that some of these strategies are inherently more imitable than others. Table 1 orders the strategies in this way, the control strategy is assumed to be the easiest to replicate elsewhere, the creative strategy being the most difficult. However, to suggest that the control regime may be the easiest to replicate 
may be correct in general terms, but this would not preclude a corporation from enacting this strategy in a highly specific, non-imitable way. But the main thrust of this argument is that the strategies to the left of Table 1 are generally more understandable, and their implementation is more straightforward than those to the right of the table.

One of the four strategies is likely to be inherently more constrained than the others. This is the scale strategy, because this strategy produces finite resources in the form of centrally managed processes. In contrast, the control, leverage and creativity strategies may be extendable across a wide range of SBUs. Many disparate businesses could benefit from a tough financial control regime, procurement skills could be leveraged across a wide variety of firms, and differing combinations of complementary SBUs can be brought into creative dialogue.

However, we would expect that at some point a particular congruent strategy would produce diminishing returns. For instance, scale resources are exhausted as the minimum efficient scale is achieved, or opportunities to leverage established resources into other SBUs have been fully exploited. Or there could be few further gains to be had from a control regime, or know-how advantages have been fully realised or the creative benefits from combining different knowledge and experience across the SBUs have been played out. Once these diminishing returns to a strategy have set in what can the centre do to rejuvenate the corporate resource creation process?

The corporate centre could try to significantly change the composition of the SBUs comprising the group. Divesting any divisions which are no longer enjoying a value enhancing relationship with the centre, and acquiring appropriate new businesses which can 
benefit as part of the existing corporate configuration, may rejuvenate the corporate resource creation process.

However, this reapplication of the existing congruent strategy works well for only two of our corporate configurations. The control configuration and the scale 1 configuration (where support activities have been centralised) can rotate their portfolios of SBUs and continue to create value because their corporate centres already require acquisition dynamic capabilities (as shown in Table 1). Also, individual SBUs within these configurations have a relatively low level of integration within the group and minimal co-ordination is required across the SBUs in such groups. This makes it much easier to unbundle any particular SBU from the businesses remaining within the group. The realisable value of the divested businesses is likely to be closer to its full economic value due to the emphasis in both these configurations' performance measures on the individual SBUs stand-alone profitability.

The increased levels of co-ordination and integration in the other configurations make it more difficult both to divest existing SBUs for full value and to regularly add significant acquired SBUs, as opposed to developing new SBUs organically within the group. At this point there is little further benefit to be had from the continuation of the congruent strategy. This is where the possibility of "divergent" strategies emerges.

\section{Divergent Strategies}

In a divergent strategy the centre pursues a value adding strategy that appears to be at odds with the embedded strategy pursued within the SBUs. For example, if the SBUs have been pursuing creative strategies that have run their course, the centre changes its focus to try to achieve scale or financial control advantages. Similarly, where cost advantages have been 
fully exploited, the centre shifts attention and focus to the encouragement of know-how creation.

These alternatives are diagrammatically represented in Figure 3. The vertical axis of Figure 3 distinguishes where changes in the focus of the corporate centre take place. Thus, the corporate centre could change its focus from Creativity to Financial Control because it believed that the value creation potential of its original configuration was fully played out. The horizontal axis considers whether the composition of the SBUs within the group has changed. This juxtaposition suggests four possibilities, ranging from "no change" with the inevitability of diminishing returns in the long term, to "all change" with the probable result of great confusion within the group. The divergent corporate strategy means that the corporate centre is challenging the SBUs in a very different way. This could be achieved simply by changing the performance measures used within the group. For example, in a group that had been implementing a creative configuration strategy, the SBU performance measures would emphasise the adherence to corporate values, the degree of collaboration on new cross-divisional ventures and the sharing of complementary knowledge with other SBUs and the centre. A divergent corporate strategy could be introduced by changing to performance measures that emphasised the profitability of individual SBUs.

\section{Insert Figure 3 about here}

This change would probably result in a rapid movement towards internal transfer pricing and royalty agreements for any shared knowledge or collaborative ventures, together with a much harder financial evaluation of any cross-divisional initiatives, and rigorous questioning of the real value added by adhering to the corporate 'values'. In some creative groups, where a lack 
of financial rigour and challenge has resulted in wasteful expenditures, such a divergent corporate strategy may initially create substantial added value. However, the sustainability of this type of divergent strategy can be questioned, as can the current corporate centre's capabilities to implement this type of change successfully.

A potentially more sustainable divergent strategy can be where the group has been implementing a very tough financial control regime across its range of SBUs. The emphasis on financial performance of individual SBUs normally results in a limited degree of integration among the SBUs and, for this type of corporate configuration, this is not a problem. However if this corporate strategy is now reaping diminishing returns so that individual SBU performance cannot be significantly further improved, the corporate centre may wish to implement a divergent corporate strategy.

This could take the form of seeking to leverage existing resources more widely across the group. Thus the centre now needs the dynamic capabilities of replication and transferring, which involve identifying which existing resources have a wider potential application and then codifying these into explicit knowledge so that they can be shared among the other relevant SBUs. As with the previous example this transformation requires both that the corporate centre changes its dynamic capabilities quite significantly as well as altering the performance measures used within the group. However the resulting strategy, if successfully implemented, is much more sustainable. Clearly, a constraint on the possibilities for leveraging know-how here is the diversity of the SBUs. Some rationalisation and re-grouping may be required to avoid the imposition of inappropriate systems onto some SBUs where these add no value. 
It is therefore not surprising that divergent corporate strategies often coincide with a change in the top management at the corporate centre, although there are examples of these divergent strategies being implemented by existing management teams. The marketing services group, WPP, would appear relatively recently to have migrated away from its original financial controls configuration to the more integrated, but also more value adding, leverage configuration. The challenge for the corporate centre is to maintain a positive creative tension between itself and the SBUs during this dramatic change, rather than allowing the situation to degenerate into value destroying confusion as SBU managers struggle to cope with the new roles and expectations within the group.

The most dramatic opportunity for major confusion in a group can be achieved by changing both dimensions of Figure 3 at the same time. In other words, the corporate centre changes its configuration at the same time as it radically changes the composition of the group. This would appear to be at the heart of the recent problems of Marconi (GEC as was), and to have contributed to the corporate problems at both BT and ICI. However, changing both dimensions could work, if the group acquires businesses for which its new corporate configuration should be relevant and value adding. In practice neither the corporate centre nor the SBUs (and certainly not the shareholders and other stakeholders in the group) now have any clear frames of reference or relevant experience to rely on; consequently the top right hand box of Figure 3 tends to result in an intolerable level of confusion across the group with a consequent destruction of shareholder value. 
The challenges of these creative tension strategies are great, and they are unlikely to flourish unless a congruent strategy has been played out. This is because the individual SBUs within the group need to have a strongly embedded strategy orientation, so that the new conflicting orientation can play off against this established momentum. In the absence of this embedded stability the pursuit of divergent strategies would just cause confusion, and result in the destruction of shareholder value.

This is diagrammatically illustrated in Figure 4 where the long term diminishing returns from any single corporate configuration are shown as the flattening curve of shareholder value creation over time. As the curve flattens, the possibility of a change in the focus of the corporate centre becomes more attractive. However, it is critical for the continued creation of shareholder value that the change in focus is to a value adding divergent strategy rather than to a value destroying incoherent strategy, under which confusion is generated by the excessive disruption caused by changing both the corporate centre configuration and the composition of the group at the same time.

\section{Conclusion}

We have set out an approach to corporate level strategy derived from the recent developments in RBV, notably the notion of dynamic capabilities. Three higher level capabilities identified by Teece $e t$ al, (reconfiguration, replication and learning) have informed our exploration of congruent resource creating strategies. Corporations can create resources, through reconfiguration, by consolidating support activities, and by centralising core processes to achieve scale advantages. New resources can be created at SBU level where existing knowhow is replicated, which we have referred to as the leverage strategy. SBU-level learning can 
be encouraged by the corporate centre, as in the creativity strategy, or it can be provoked by the financial control strategy.

Through an exploration of the likely organisational requirements of each strategy, and drawing on Mintzberg's configurational approach, we concluded that some of these strategies could feasibly be pursued in tandem, but other combinations were not feasible. Pursuing any congruent strategy vigorously will eventually result in a slowing of the resource creation process. We suggested that corporations could explore divergent strategies which would seek to develop resources in different ways to the embedded congruent strategy. Finally, using standard RBV reasoning, we explored the sustainability of each strategy. The next challenge is to empirically explore these ideas. This could be done through an examination of extant cases of corporations, or through the gathering of fresh data. 


\section{REFERENCES}

Barney, J.B. (1991). 'Firm resources and sustained competitive advantage'. Journal of Management, 17(1): 99-120; Dierickx, I. and K. Cool. (1989). 'Asset stock accumulation and sustainability of competitive advantage', Management Science, 35(12): 1504-1511.

Teece, D. J., G. Pisano and A. Shuen. (1997). 'Dynamic capabilities and strategic management', Strategic Management Journal, 18(7): 509-533; Eisenhardt, K. M. and J. A. Martin. (2000). 'Dynamic capabilities: What are they?'. Strategic Management Journal, 21(10/11):1105-1121.

3 Porter, M.J. 1980. Competitive Strategy. New York: The Free Press; Porter, M. J. 1985. Competitive Advantage, New York: The Free Press.

4 Mintzberg, H. (1979). The Structuring of Organizations. Englewood-Cliffs, NJ: Prentice-Hall; Mintzberg, H. (1983). Power In And Around Organizations. Englewood Cliffs, NJ: Prentice-Hall.

5 Chandler, A. D. (1962). Strategy and Structure, Cambridge, Mass. MIT Press; Burns, T. and G. M. Stalker. (1961). The management of innovation. London: Tavistock; Lawrence, P. and J. Lorsch. (1967). Organization and environment. Boston: Harvard University Press.

6 Miles, R. E. and C. C. Snow. (1978). Organizational Strategy, Structure and Process. New York: McGraw Hill. 
7 Porter, M.J. 1980. Competitive Strategy. New York: The Free Press; Porter, M. J. 1985. Competitive Advantage, New York: The Free Press.

8 Mintzberg, H. and J. A. Waters. (1985). 'Of strategies, deliberate, and emergent'. 


\section{Table 1 Four Configurations}

\begin{tabular}{|c|c|c|c|c|c|}
\hline & & Financial Control & Scale & Leverage & Creativity \\
\hline & Dynamic Capabilities & $\begin{array}{l}\text { (Provoked) Learning } \\
\text { Acquisition, } \\
\text { Resource Allocation }\end{array}$ & $\begin{array}{l}\text { Acquisitions } \\
\text { Process and Product } \\
\text { Development } \\
\end{array}$ & $\begin{array}{l}\text { Replication, } \\
\text { Transferring }\end{array}$ & $\begin{array}{l}\text { Connecting, Learning } \\
\text { Collaborating }\end{array}$ \\
\hline & SBU Strategy Autonomy & Autonomy on means not ends & $\begin{array}{l}\text { Constrained by process } \\
\text { provision }\end{array}$ & $\begin{array}{l}\text { Constrained by standard } \\
\text { processes }\end{array}$ & $\begin{array}{l}\text { Constrained by core } \\
\text { values }\end{array}$ \\
\hline & SBU Performance Measures & Profitability & $\begin{array}{l}\text { Mixed; e.g. cost reduction } \\
\text { plus sales targets }\end{array}$ & $\begin{array}{l}\text { Plural, including } \\
\text { conformance to systems }\end{array}$ & $\begin{array}{l}\text { Plural, including } \\
\text { adherence to corporate } \\
\text { values }\end{array}$ \\
\hline & Co-ordination across levels & Minimal & $\begin{array}{l}\text { Strong, if core processes } \\
\text { centralised }\end{array}$ & $\begin{array}{l}\text { Required re: } \\
\text { standard systems }\end{array}$ & Shared values \\
\hline & Co-ordination across SBUs & None required & Standard processes & $\begin{array}{l}\text { Co-operation in knowledge } \\
\text { transfer }\end{array}$ & $\begin{array}{l}\text { Sharing ideas, } \\
\text { collaborating on new } \\
\text { ventures }\end{array}$ \\
\hline \multirow{5}{*}{$\begin{array}{c}\text { Design } \\
\text { Parameters }\end{array}$} & SBU Similarity & Can benefit from control regime & Same activities & $\begin{array}{l}\text { Can benefit from same } \\
\text { systems }\end{array}$ & $\begin{array}{l}\text { Complementary } \\
\text { knowledge }\end{array}$ \\
\hline & Role of Centre & Operates financial control regime & Performs activities & $\begin{array}{l}\text { Codifies and transfers } \\
\text { know-how }\end{array}$ & $\begin{array}{l}\text { Encourages creativity } \\
\text { across SBUs }\end{array}$ \\
\hline & $\begin{array}{l}\text { Predominant } \\
\text { co-ordinating mechanism }\end{array}$ & $\begin{array}{l}\text { Standardisation of financial } \\
\text { outputs }\end{array}$ & $\begin{array}{l}\text { Direct supervision of } \\
\text { standardised activities by } \\
\text { centre }\end{array}$ & $\begin{array}{l}\text { Standardisation of systems } \\
\text { and skills }\end{array}$ & $\begin{array}{l}\text { Standardisation of } \\
\text { values }\end{array}$ \\
\hline & Predominant part of the organisation & Strategic apex & $\begin{array}{l}\text { Centralised operating core } \\
\text { and middle line }\end{array}$ & Technostructure & Culture/ideology \\
\hline & Location of created resources & SBUs & Centre & SBUs & SBUs \\
\hline
\end{tabular}


Figure 1: Four Resource Creating Strategies

Financial Control

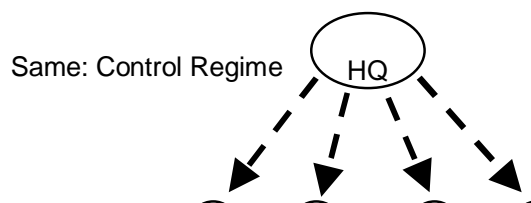

(A) (B) (C) (D)

Scale 1

Same: Central Support Activities

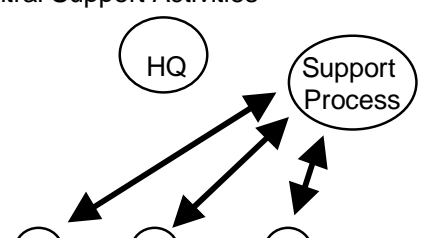

(A)

(B)

(C)

Scale 2

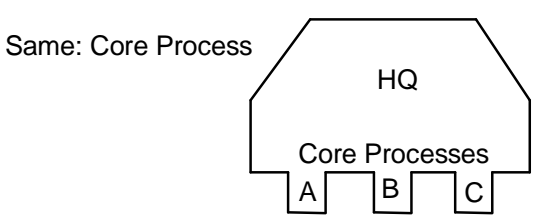

Leverage

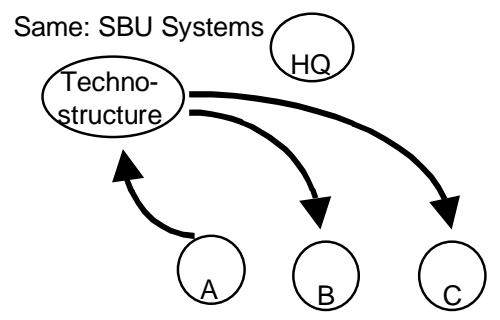

Creativity

Complementary Knowledge

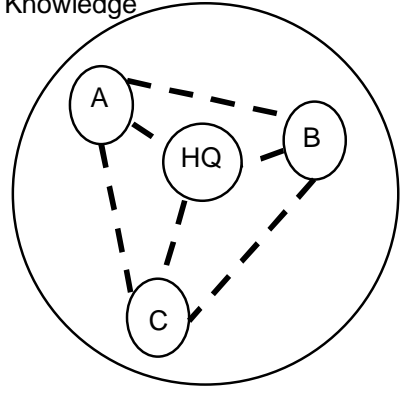


Figure 2: Comparing the Strategies on Four Design Parameters

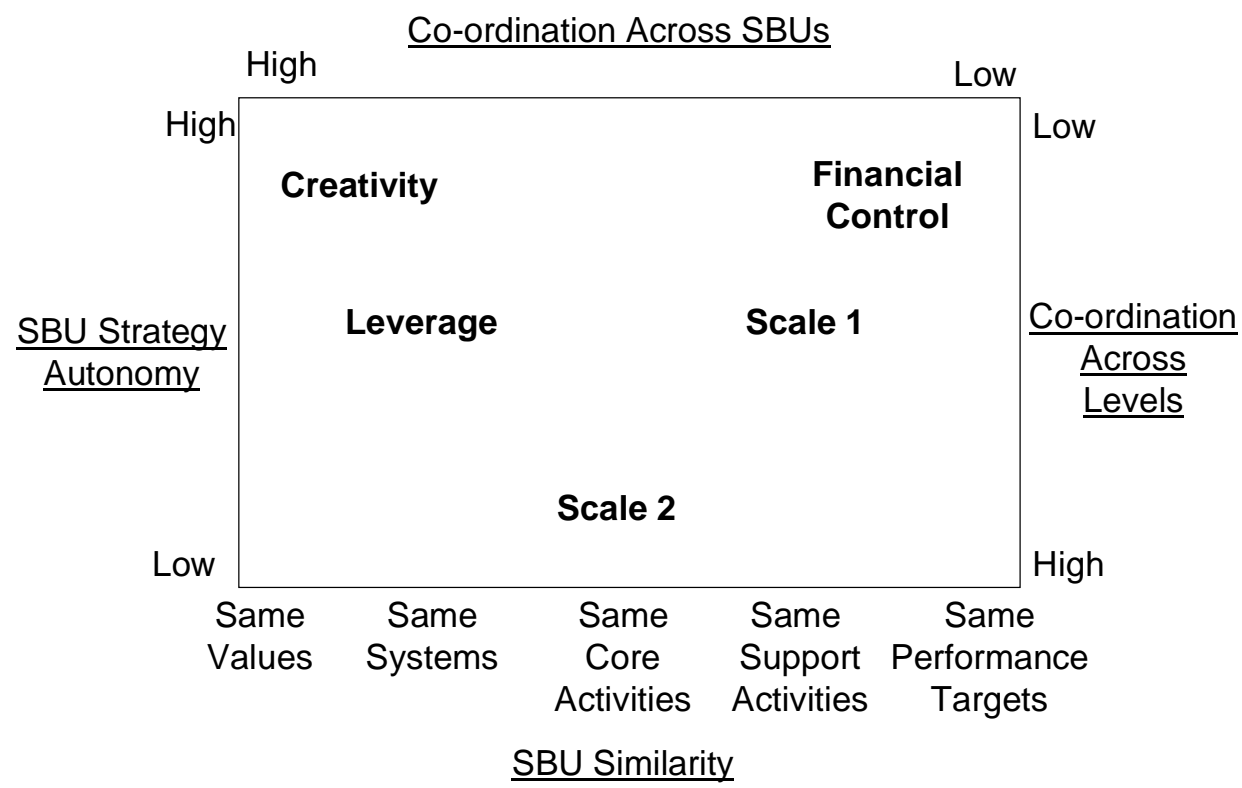

Figure 3: Introducing Divergent Corporate Strategies

Corporate

Centre

Configuration

Same

\begin{tabular}{|l|c|}
\hline $\begin{array}{l}\text { DIVERGENT } \\
\text { CORPORATE } \\
\text { STRATEGY } \\
\text { - Creative } \\
\text { Tension }\end{array}$ & $\begin{array}{l}\text { INCOHERENT } \\
\text { CORPORATE } \\
\text { STRATEGY } \\
\text { - Confusion resulting } \\
\text { in destruction of value }\end{array}$ \\
\hline CONGRUENT & STRATEGIES \\
$\begin{array}{l}\text { Diminishing } \\
\text { Returns eventually } \\
\text { applies }\end{array}$ & $\begin{array}{l}\text { Acquisition and } \\
\text { Divestment } \\
\text { Strategy }\end{array}$ \\
\multicolumn{2}{|c|}{ Same }
\end{tabular}

Corporate Composition

(i.e. Portfolio of SBUs) 
Figure 4: Diminishing Returns to Congruent Strategies

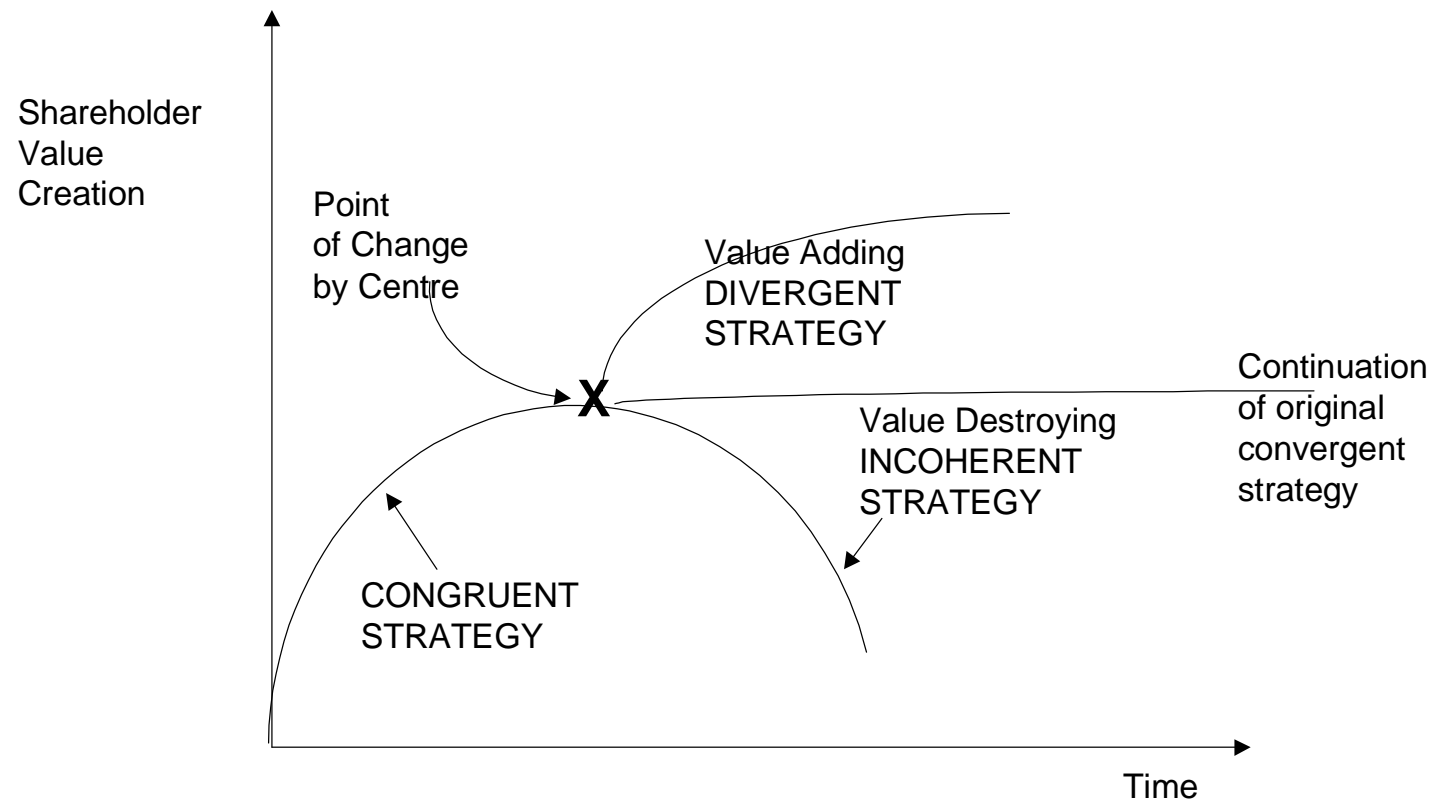

